\title{
Birdwatching Potency at Liwa Botanical Garden, West Lampung
}

\author{
Agis Agita*, Nuning Nurcahyani, M. Kanedi, Hendri Busman \\ Jurusan Biologi, Fakultas Matematika dan IImu Pengetahuan Alam Universitas Lampung \\ Jalan. Prof. Soemantri Brojonegoro, Bandar Lampung, 35145 \\ Email : Agisagita1998@gmail.com
}

\begin{abstract}
The Liwa Botanical Garden is located in Kubu Perahu Village, Balik Bukit District, West Lampung Regency. The Liwa Botanical Garden has an area of 86 ha, built in 2007 with the theme of Indonesian Ornamental Plants. The Liwa Botanical Garden is one of the destinations that is being developed for tourism activities and used as a recreational object. One of the functions of the Liwa Botanical Garden is as a tourist spot. Plants in the Liwa Botanical Garden are so beautiful. The Liwa Botanical Garden is a bird habitat because it has an abundant source of food for birds. Therefore it is necessary to do an inventory of bird species by conducting research to find out potential bird species that are used as tourist attractions (birdwatching) at the Liwa Botanical Garden. This research was conducted on October 2019. The method used was the point count method and rapid assessment. Based on field observations found 14 species of birds that are not protected and only 1 species of birds included in the protected category. And found 8 types of plants, namely 5 types of trees, 1 species of ferns, 1 species of bushes, and 1 type of reeds
\end{abstract}

Keywords: Liwa Botanical Garden, bird species inventory, birdwatching, point count, rapid assessment.

\section{PENDAHULUAN}

Burung merupakan satwa yang memiliki peran penting bagi suatu ekosistem maupun bagi kehidupan manusia. Oleh karena itu keberadaan burung perlu dipertahankan (Rusmendro, 2009). Kehadiran burung merupakan penyeimbang lingkungan dalam komponen ekosistem, karena burung memiliki peran sebagai satwa pemangsa puncak, satwa pemecah biji, satwa penyerbuk, dan satwa predator hama (Ramdhani, 2008).

Birdwatching merupakan kegiatan rekreasi mengamati burung di alam liar dengan mata telanjang dan juga bisa menggunakan alat bantu seperti teropong. atau sekadar mendengarkan suara kicauan burung dan merupakan salah satu teknik konservasi sebagai media untuk meningkatkan kesadaran tentang pentingnya konservasi burung. Wisata pengamatan burung liar (birdwatching) merupakan salah satu bentuk wisata alam yang sejak tahun 2000-an terus dikembangkan di Indonesia.

Keanekaragaman jenis burung tersebut jika dimanfaatkan sebagai objek wisata birdwatching akan memberikan dampak positif bagi masyarakat di sekitarnya, seperti memberikan manfaat ekonomi bagi masyarakat sekitar karena banyaknya wisatawan yang akan melakukan kunjungan ke daerah tersebut, dan juga bisa kelestarian jenis-jenis burung tersebut (Widyasari, 2013).

Kebun Raya adalah aset strategis dalam mengurangi dampak perubahan iklim global dan dapat berfungsi sebagai tempat konservasi ex situ, tempat rekreasi, tempat pendidikan, dan juga sebagai tempat penelitian (Heywood, 2010). Kebun Raya Liwa terletak di Desa Kubu Perahu, Kecamatan Balik Bukit, Kabupaten Lampung Barat. Kebun Raya Liwa memiliki luas 86 ha, dibangun pada tahun 2007 bertemakan Tanaman Hias Indonesia. Tanaman di Kebun Raya Liwa 
sangat asri sehingga Kebun Raya Liwa dapat menjadi habitat untuk burung.

Penelitian ini bertujuan untuk mengetahui jenis burung yang berpotensial dijadikan objek wisata birdwatching dan tumbuhan yang berpotensi sebagai habitat burung. Untuk itu, maka penting dilakukan pengembangan wisata di Kebun Raya Liwa. Hasil penelitian ini dapat dijadikan referensi dalam perencanaan pengembangan wisata birdwatching di Kebun Raya Liwa.

\section{METODE PENELITIAN}

\section{Waktu dan Tempat Penelitian}

Penelitian ini dilaksanakan pada tanggal 12 - 20 Oktober 2019 di Kebun Raya Liwa Lampung Barat yang merupakan kerja sama jurusan Biologi FMIPA Universitas Lampung dengan UPTD Kebun Raya Liwa Lampung Barat.

\section{Alat dan Bahan Penelitian}

Alat yang digunakan dalam pengambilan data yaitu teropong binokuler Nikon Trailblazer yang digunakan sebagai alat bantu pengamatan burung dalam jarak jauh, buku panduan lapangan Jenis Burung di Sumatera, Jawa, Bali, dan Kalimantan (MacKinnon et al., 2010) yang digunakan sebagai alat bantu dalam melakukan identifikasi jenis burung yang ditemukan, lembar kerja (work sheet) adalah lembar kerja yang digunakan untuk mencatat hasil pengamatan di lapangan, alat tulis digunakan untuk mencatat, kamera digunakan untuk mengambil gambar jenis burung yang ditemukan saat melakukan pengamatan, jam digital digunakan untuk melihat waktu saat burung ditemukan. Objek yang diamati yaitu burung dan tumbuhan yang terdapat di Kebun Raya Liwa Lampung Barat.

\section{Metode Pengambilan Data}

Pengambilan data jenis burung yang potensial dijadikan objek wisata birdwatching dilakukan dengan menggunakan metode point count (titik hitung). Pengamatan dilakukan selama 9 hari pada lokasi yang sudah ditentukan yaitu lokasi A sekitar kantor Kebun Raya Liwa, lokasi B taman araceae dan lokasi C perbatasan kantor Kebun Raya Liwa dengan hutan dilakukan pada pagi hari pukul 06.00-08.00 WIB dan sore hari pada pukul 16.00-18.00 WIB selama 60 menit (15 menit untuk pengamatan disetiap lokasi dan 15 menit untuk berjalan ke lokasi pengamatan selanjutnya). Radius pengamatan disetiap lokasi adalah $50 \mathrm{~m}$ dan jarak antar lokasi $150 \mathrm{~m}$, hal ini untuk menghindari agar tidak terjadi pengulangan pencatatan jenis burung.

Pendataan jenis tumbuhan dilakukan dengan metode rapid assessment yaitu mencatat jenis tumbuhan yang menjadi tempat burung beraktivitas seperti bertengger, mencari makan, berkicau, dan berkembang biak untuk mengetahui pengaruh jenis tumbuhan terhadap keberadaan dan aktivitas burung.

\section{Analisis Data}

Jenis metode penelitian ini adalah analisis deskriptif, adapun pengertian dari analisis deskriptif merupakan analisis yang dilakukan dengan cara menguraikan hasil penelitian yang diperoleh secara kritis sesuai dengan teori (Sugiyono, 2013). Analisis data hasil inventarisasi jenis burung yang berpotensi untuk pengembangan wisata birdwatching di Kebun Raya Liwa disajikan dalam bentuk tabel, kemudian mengidentifikasi jenis burung yang ditemukan. Data tersebut dianalisis secara deskriptif berdasarkan hasil pengamatan yang dilakukan. Data pengaruh tumbuhan terhadap keberadaan dan aktivitas burung juga dianalisis secara deskriftif yaitu dengan menjabarkan jenis tumbuhan yang ditemukan di lokasi penelitian dan kemudian dibahas pengaruhnya terhadap keberadaan dan aktivitas burung.

\section{HASIL DAN PEMBAHASAN}

\section{Inventarisasi Jenis Burung}

Hasil inventarisasi keberadaan jenis burung yang telah dilakukan selama 9 hari di Kebun Raya Liwa Lampung Barat, ditemukan sebanyak 15 spesies burung 
dengan total 466 individu yang berasal dari 9 famili. Jenis burung yang ditemukan antara lain adalah cekakak sungai (Todirhamphus chloris), walet sapi (Collocalia esculenta), perkutut (Geopelia striata), cucak kutilang (Pycnonotus aurigaster), cucak kuning (Pycnonotus melanicterus), punai gading (Treron vernans), punai jambu/walik jambu (Ptilinopus jambu), uncal buau (Macropygia emiliana), merbah crukcuk (Pycnonotus goiavier), bentet kelabu (Lanius schach goiavier), tekukur (Streptopelia chinensis), kicuit batu (Motacilla cinere), kareo padi (Amaurornis phoenicuru), cabai bunga api (Dicaeum trigonostigma), dan cinenen kelabu (Orthotomus ruficeps.

Banyak dijumpai jenis burung pemakan serangga. Jenis tanaman seperti semak dan alang-alang menjadi habitat bagi serangga, dan hal tersebut mengundang kehadiran burung pemakan serangga. Berdasarkan pengamatan di lapangan sering pula dijumpai aktivitas burung sedang bertengger atau bersuara di pohon. Pohon-pohon yang dimanfaatkan oleh burung untuk bertengger tidak menentu jenisnya. Keberadaan jenis burung sangat berpengaruh terhadap jenis pohon yang ada di Kebun Raya Liwa.

\section{Inventarisasi Jenis Pohon}

Hasil inventarisasi jenis tumbuhan yang berpengaruh terhadap keberadaan jenis burung di Kebun Raya Liwa, ditemukan 8 jenis tumbuhan yaitu pulai (Alstonia scholaris), beluntas (Pluchea indica), baobab (Adansonia), kelapa sawit (Elaeis guineensis), ki tenjo (Anisoptera costata), paku andam (Dicranopteris linearis), alang-alang (Imperata cylindrica), dan loleba (Bambusa atra lindl).

Paling sering ditemukan aktivitas burung lebih banyak bertengger pada suatu pohon dan hanya terlihat beberapa burung sedang mencari makan misalnya burung walik jambu yang terlihat sedang bertengger dan memakan bunga di semak-semak yang berupa tumbuhan beluntas. Bunga sangat berpengaruh pada kehadiran atau keberadaan burung Tabel 1. Daftar jenis burung yang terdapat di Kebun Raya Liwa Lampung Barat karena bisa menyediakan nektar dan serangga sehingga mengundang kedatangan burung-burung pemakan nektar dan serangga karena berdasar hasil pengamatan dilapangan banyak ditemukan jenis burung pemakan serangga di Kebun Raya Liwa. Keanekaragaman jenis burung dipengaruhi oleh keanekaragaman tipe habitat seperti faktor struktur habitat dan ketersediaan pakan (Rusmendro, 2004). Di lokasi pengamatan ditemukan juga jenis burung pemakan biji-bijian karena beberapa tumbuhan di lokasi tersebut memproduksi buah yang menjadi sumber pakan oleh jenis burung pemakan bijibijian. Menurut Setyo dan Takadjandji (2007), beberapa karakteristik tumbuhan yang cocok dan dapat dipelihara untuk menyiapkan lingkungan alami bagi burung adalah buahnya dapat dijadikan sumber pakan burung, berbuah sepanjang tahun.

Pada saat melakukan penelitian sedang mengalami musim kemarau dimana kondisi tumbuh-tumbuhanpun sedang tidak bereproduksi menghasilkan bunga dan buah sehingga tidak dapat menyediakan pakan untuk kebutuhan burung. Perlu dilakukan penambahan tumbuhan di Kebun Raya Liwa dengan menanami tumbuhan yang memproduksi biji-bijian, nektar, yang dapat menarik serangga sehingga menyediakan pakan bagi burung sepanjang tahun (Slattery et al., 2003). Diperlukan juga penambahan pohon yang menjadi habitat serangga agar dapat mengundang kehadiran burung (Whitten et al.,1999). Habitat yang baik di dalamnya mengandung bermacam-macam sumber pakan, memungkinkan memiliki jenis burung yang banyak (Setiawan et al., 2006).

\section{KESIMPULAN}

Berdasarkan penelitian yang telah dilakukan di Kebun Raya Liwa Lampung Barat dapat disimpulkan bahwa ditemukan 15 jenis burung yang dapat dijadikan objek potensial untuk pengembangan wisata birdwatching dan 8 jenis tumbuhan yang berpotensi dijadikan sebagai habitat burung. 


\begin{tabular}{llll}
\hline No & Nama Jenis & Nama llmiah & Status IUCN \\
\hline 1 & Cekakak Sungai & Todirhamphus chloris & Resiko rendah \\
2 & Walet Sapi & Risiko Rendah \\
& & Geopelia striata & Resiko rendah \\
3 & Perkutut & Pycnonotus aurigaster & Resiko rendah \\
4 & Cucak Kutilang & Pycnonotus melanicterus & Resiko rendah \\
5 & Cucak Kuning & Treron vernans & Resiko rendah \\
6 & Punai Gading & Ptilinopus jambu & Hampir terancam \\
7 & Punai Jambu Walik Jambu & Resiko rendah \\
8 & Uncal Buau & Macropygia emiliana & \\
& & & Resiko rendah \\
9 & Merbah Crukcuk & Pycnonotus goiavier & Resiko rendah \\
10 & Bentet Kelabu & Lanius schach & Resiko rendah \\
11 & Tekukur & Streptopelia chinensis & Resiko rendah \\
12 & Kicuit Batu & Motacilla cinerea & Resiko rendah \\
13 & Kareo Padi & Amaurornis phoenicurus & Resiko rendah \\
14 & Cabai Bunga Api & Dicaeum trigonostigma & Resiko rendah \\
15 & Cinenen Kelabu & Orthotomus ruficeps & \\
\hline
\end{tabular}

Tabel 2. Daftar Jenis Tumbuhan yang Dijadikan Tempat Beraktivitas Burung

\begin{tabular}{llll}
\hline No & Nama Lokal & Nama Ilmiah & Aktivitas Burung \\
\hline 1 & Pulai & Alstonia scholaris & Bertengger dan bermain \\
2 & Beluntas & Pluchea indica & Bertengger dan makan \\
3 & Baobab & Adansonia & Bertengger dan bermain \\
4 & Kelapa Sawit & Elaeis guineensis & Bertengger \\
5 & Ki Tenjo & Anisoptera costata & Bertengger dan bermain \\
6 & Paku Andam & Dicranopteris linearis & Mencari makan \\
7 & Alang-alang & Imperata cylindrica & Bermain dan mencari makan \\
8 & Loleba & Bambusa atra lindl & Bertengger \\
\hline
\end{tabular}

\section{UCAPAN TERIMAKASIH}

Terimakasih kepada Badan Penelitian dan Pengembangan Daerah Balitbangda Kabupaten Lampung Barat yang telah memberikan izin dan kepada Bapak Sukimin, S.IP. MM. selaku Kepala UPTD Pengelolaan Kebun Raya Liwa beserta seluruh staff Kebun Raya Liwa telah memberikan bantuan sehingga penelitian ini dapat berjalan dengan baik.

\section{DAFTAR PUSTAKA}

Heywood, H. V. (2010). The role of botanic gardens as resource and introduction centresin the face of global change. Journal Biodiversity Conservation.

Mac Kinnon, Phillips, J.K., \& Van Balen, B. (2010). Seri Panduan Lapangan Burung-burung di Sumatera,
Jawa, Bali, dan Kalimantan. LIPI. Bogor.

Ramdhani. (2008). Keanekaragaman Burung dan Dasar - Dasar Birdwatching di http://www.deriramdhani's.com (diakses tanggal 10 Januari 2020).

Rohadi, D., \& Harianto, S.P. (2011). Keanekaragaman Jenis Burung di Rawa Universitas Lampung (Skripsi). Universitas Lampung. Bandar Lampung.

Rusmendro, H. (2004). Bahan Kuliah Ornithology. Universitas Nasional. Jakarta.

Setiawan, A., Alikodra, H.S., Gunawan, A., \& Darneidi, D. (2006). Keanekaragaman Jenis Pohon Dan Burung Di Beberapa Areal 
11 / Agita, A., Nurcahyani, N., Kanedi, M., Busman, H.

Hutan Kota Bandar Lampung. Manajemen Hutan Tropika.

Bandar Lampung.

Setyo, P.M., \& Takadjandji. (2007). Konservasi Ex Situ Burung Endemik Langka Melalui Penangkaran. Prosiding Expose Hasil-hasil Penelitian. Pusat Litbang Hutan dan Konservasi Alam. Bogor.

Slaterry, B.E., Reshetiloff, K., \& Zwicker, S.M. (2003). Native Plants for Wildlife Habitat and Conservation Landscaping. Native Plant Center.
Sugiyono. (2013). Metode Penelitian Kuantitatif dan kualitatif. Alfabeta. Bandung.

Whitten, T., Roehayat, E.S., \& Suraya, A.A. (1999). Ekologi Jawa dan Bali. Prehallindo. Jakarta.

Widyasari, K., Hakim, L., \& Yanuwiadi, B. (2013). Kajian jenis - jenis burung di Desa Ngadas sebagai dasar perencanaan jalur pengamatan burung (birdwatching). Journal of Indonesian Tourism and Development Studies. 